\title{
Variability of ionospheric TEC during solar and geomagnetic minima (2008 and 2009): external high speed stream drivers
}

\author{
O. P. Verkhoglyadova ${ }^{1,2}$, B. T. Tsurutani ${ }^{1}$, A. J. Mannucci ${ }^{1}$, M. G. Mlynczak $^{3}$, L. A. Hunt ${ }^{4}$, and T. Runge ${ }^{1}$ \\ ${ }^{1}$ Jet Propulsion Laboratory, California Institute of Technology, Pasadena, CA, USA \\ ${ }^{2}$ Center for Space and Aeronomy Research, UAH, Huntsville, AL, USA \\ ${ }^{3}$ NASA Langley Research Center, Hampton, VA, USA \\ ${ }^{4}$ Sciences Systems and Applications, Inc., Hampton, VA, USA \\ Correspondence to: O. P. Verkhoglyadova (olga.verkhoglyadova@jpl.nasa.gov)
}

Received: 14 July 2012 - Revised: 10 December 2012 - Accepted: 22 January 2013 - Published: 19 February 2013

\begin{abstract}
We study solar wind-ionosphere coupling through the late declining phase/solar minimum and geomagnetic minimum phases during the last solar cycle (SC23) - 2008 and 2009. This interval was characterized by sequences of high-speed solar wind streams (HSSs). The concomitant geomagnetic response was moderate geomagnetic storms and high-intensity, long-duration continuous auroral activity (HILDCAA) events. The JPL Global Ionospheric Map (GIM) software and the GPS total electron content (TEC) database were used to calculate the vertical TEC (VTEC) and estimate daily averaged values in separate latitude and local time ranges. Our results show distinct low- and midlatitude VTEC responses to HSSs during this interval, with the low-latitude daytime daily averaged values increasing by up to 33 TECU (annual average of $~ 20$ TECU) near local noon (12:00 to 14:00 LT) in 2008. In 2009 during the minimum geomagnetic activity (MGA) interval, the response to HSSs was a maximum of $\sim 30$ TECU increases with a slightly lower average value than in 2008. There was a weak nighttime ionospheric response to the HSSs. A well-studied solar cycle declining phase interval, 10-22 October 2003, was analyzed for comparative purposes, with daytime lowlatitude VTEC peak values of up to $~ 58$ TECU (event average of $\sim 55$ TECU). The ionospheric VTEC changes during 2008-2009 were similar but $\sim 60 \%$ less intense on average. There is an evidence of correlations of filtered daily averaged VTEC data with Ap index and solar wind speed.

We use the infrared $\mathrm{NO}$ and $\mathrm{CO}_{2}$ emission data obtained with SABER on TIMED as a proxy for the radiation balance of the thermosphere. It is shown that infrared emissions increase during HSS events possibly due to increased energy
\end{abstract}

input into the auroral region associated with HILDCAAs. The 2008-2009 HSS intervals were $~ 85 \%$ less intense than the 2003 early declining phase event, with annual averages of daily infrared NO emission power of $\sim 3.3 \times 10^{10} \mathrm{~W}$ and $2.7 \times 10^{10} \mathrm{~W}$ in 2008 and 2009 , respectively. The roles of disturbance dynamos caused by high-latitude winds (due to particle precipitation and Joule heating in the auroral zones) and of prompt penetrating electric fields (PPEFs) in the solar wind-ionosphere coupling during these intervals are discussed. A correlation between geoeffective interplanetary electric field components and HSS intervals is shown. Both PPEF and disturbance dynamo mechanisms could play important roles in solar wind-ionosphere coupling during prolonged (up to days) external driving within HILDCAA intervals.

Keywords. Ionosphere (Ionosphere-magnetosphere interactions; Ionospheric disturbances) - Magnetospheric physics (Storms and substorms)

\section{Introduction and brief review of high-speed stream effects in ionosphere and thermosphere}

The solar (sunspot) declining phase is characterized by lowlatitude coronal holes (Temmer et al., 2007; de Toma, 2011) from which high-speed streams (HSSs) emanate (Sheeley et al., 1976, 1977; Tsurutani et al., 1995, 2006a). Luhmann et al. (2002), based on extensive database of solar observations, have shown that maximum values of the solar wind velocity associated with open flux tubes (coronal holes) are attained during the declining and minimum phases of the solar 
cycle. During the propagation of the HSSs from the Sun to Earth, they interact with slow speed streams, forming corotating interaction regions or CIRs. These CIRs interact with the Earth's magnetosphere and cause moderate geomagnetic storm main phases. The main difference of this type of geomagnetic activity from those associated with interplanetary coronal mass ejections (ICMEs) during solar maximum is its relatively moderate storm intensities (Dst rarely goes below $-100 \mathrm{nT})$. The HSS proper interaction with the Earth causes high-intensity, long-duration continuous auroral activity (HILDCAA) events (see the review by Tsurutani et al. (2006a) and references therein). The long-duration storm "recovery" phases associated with the HILDCAAs can last from several to $\sim 25$ days (Tsurutani et al., 2006c). In this case there is continuous external forcing of the Earth's magnetosphere, thermosphere and ionosphere.

A connection between solar wind and the Earth's ionosphere and thermosphere during CIRs/HSSs manifests itself in $\sim 7$ and $\sim 9$ day periodicities of different physical parameters. These periodicities have been shown to exist in thermospheric density variations at CHAMP altitudes $(\sim 400 \mathrm{~km})$ (Thayer et al., 2008), thermospheric composition with GUVI on TIMED (Crowley et al., 2008), the thermospheric energy budget (Mlynczak et al., 2008), the global mean ionospheric total electron content (TEC) values (Lei et al., 2008), TEC values above CHAMP (Pedatella et al., 2010), the NmF2 in ionosonde measurements (Wang et al., 2011), and the $\mathrm{NmF} 2$ and $\mathrm{HmF} 2$ in electron density profiles at COSMIC (Ram et al., 2010). Liu et al. (2010) reported the existence of $\sim 9$ day oscillations in the topside ionosphere, further connecting the bottom ionosphere and the magnetosphere. Burns et al. (2012) used NCAR TIE-GCM to simulate ionospheric response to HSSs in 2008. They showed positive, lasting storm effects on $N m \mathrm{~F} 2$ in mid-latitude ionosphere. These results underline the importance of heliospheric drivers for ionospheric and thermospheric dynamics in the declining phase of a solar cycle.

A solar sunspot minimum is typically considered as having low to moderate geomagnetic activity, with few or no major magnetic storms occurring during this time. CIRs and HSSs are also considered the main drivers for geomagnetic activity in the recent solar minimum, but their effects are significantly diminished (Tsurutani et al., 2011a). Our study will include CIR/HSS intervals of the late declining phase and the solar minimum (2008), and the minimum geomagnetic activity interval (2009) of the SC23 solar cycle.

It is well known that energy input into the magnetosphereionosphere system during the solar declining phase, averaged over a year, can be comparable or even often higher than during solar maximum years when ICMEs dominate solar (and geomagnetic) activity (Tsurutani et al., 1995, 2006a; Kozyra et al., 2006; Guarnieri, 2006; Turner et al., 2006, 2009; Emery et al., 2009; Verkhoglyadova et al., 2011). Recurrent HSSs were found responsible for elevated energetic electron flux in the Earth's outer radiation belt during the last solar minimum (Gibson et al., 2009). Kozyra et al. (2006) have found a higher total energy deposition into the auroral atmosphere during HSS events than during solar maximum intervals. Guarnieri (2006) has shown that average electron flux causing auroras (from POLAR images) during CIR storms/high-speed streams is higher than during recovery phases of intense magnetic storms. Recently, a study by Turner et al. (2009) illustrated that, in general, CIR-driven storms were somewhat more efficient at coupling solar wind energy into the magnetosphere than ICME storms with the efficiency of energy transfer from the solar wind to magnetosphere as $73 \%$ to $\sim 63 \%$. It is important to note that about $\sim 50 \%$ of the energy is converted into Joule heating alone. An extensive study conducted by Emery et al. (2009) over three solar cycles showed that $\sim 50 \%$ of the auroral electron power is associated with HSS structures (compared to $32 \%$ in transients and ICMEs). Verkhoglyadova et al. (2011) estimated that event-integrated energy of thermospheric infrared radiation is higher during a sample HSS interval than during a CME-type storm.

It is known that the major source of heating at high latitudes is direct solar EUV, which only occurs on the dayside atmosphere. The EUV level was extremely low during the last solar minimum (Solomon et al., 2010). Here we will focus exclusively on interplanetary (solar wind) drivers for the ionospheric and atmospheric activity. Analysis of thermospheric heating in 1975-2003 based on the Dynamics Explorer had shown that Joule heating was the major contributor to variability of the thermospheric power and dominated the auroral zone (Knipp et al., 2004). Recently, Knipp et al. (2011) estimated the Poynting flux sorted by solar wind flow type. Their result showed that energy influx into the high-latitude magnetosphere between transients (ICMEs) and HSSs are about comparable. Huang et al. (2012), also using DMSP measurements, showed an increase in auroral zone Joule heating with increased solar wind speeds.

The infrared energy budget of the thermosphere throughout the solar cycle has been extensively studied by Mlynczak et al. (2007, 2008, 2010a) and Hunt et al. (2011). It has been shown that the variability in solar ultraviolet radiation controls the long-term variability of the infrared radiation from nitric oxide (NO), which cools the thermosphere. Occasionally, infrared radiation power exceeds solar radiation input (Mlynczak et al., 2008). These events were attributed to additional energy input due to geomagnetic activity (Mlynczak et al., 2010b). Lu et al. (2010) have shown that Joule heating dissipation is responsible for thermospheric temperature and NO density increases and thus radiative emission by NO in the thermosphere during geomagnetic storms. Geomagnetic/auroral activity in general is suggested to cause most of the thermospheric radiated power variability (Solomon et al., 1999; Marsh et al., 2004; Mlynczak et al., 2010b; Verkhoglyadova et al., 2011). Recurrent and continuous driving of the high-latitude magnetosphere and ionosphere by HSSs leads to increases in NO temperature and density and causes 
multi-day oscillation of NO cooling rates (Qian et al., 2010). Kozyra et al. (2006) emphasized the importance of NO production by auroral electron precipitation to the atmosphere during strong HSS activity. They mentioned consequences for coupling to the stratosphere and possible climate modification (see also Marsh et al., 2004). In this paper we will use the daily averaged power of NO infrared thermospheric radiation derived from SABER instrument measurements onboard TIMED as a proxy for auroral energy influx and highlatitude thermospheric heating.

We expect recurrent long-lasting moderate disturbances in the ionosphere and the thermosphere during the declining phase and solar minimum when HSSs are impinging on the Earth's magnetosphere. The goal of this paper is twofold: to identify the effects of HSSs on the ionosphere and atmosphere during the solar minimum and geomagnetic activity minimum phases (2008-2009). These results then will be compared to a short HSS interval during the early declining phase of the solar cycle (2003). Mechanisms for the thermospheric enhanced radiation and for the enhanced ionospheric total electron content will be discussed.

\section{Data analysis}

To study general dynamics of the vertical total electron content (VTEC) we utilize measurements from up to $\sim 200$ GPS ground sites in the GPS global network of receivers. We use a three-shell ionospheric model to convert GPS satellite-to-site measurements of line-of-sight TEC values to VTEC values above an ionospheric pierce point (Mannucci et al., 1998, 1999). Typical data cadence is $\sim 30 \mathrm{~s}$. Global data are divided into several sets within different local times and latitude ranges. Resultant VTEC data sets are averaged over daily intervals. We use the following solar magnetic coordinate system (SM) to identify geomagnetic activity effects on the equatorial and mid-latitude ionosphere. The Z-axis is chosen parallel to the north magnetic pole and the Y-axis is perpendicular to the Earth-Sun (local noon) line (Knecht and Shuman, 1985; Mannucci et al., 1998). The X-axis wobbles back and forth by $\pm 11.5^{\circ}$ once every $24 \mathrm{~h}$. In this paper we consider day-to-day global changes of the ionosphere in response to external solar wind driving.

Here we need to distinguish the late declining phase/solar minimum of the last solar cycle SC23 (2008) and the geomagnetic minimum phase (2009). Tsurutani et al. (2011a) have shown that a minimum in geomagnetic activity (MGA) is delayed relative to the solar cycle minimum to the middle to late part of 2009. They defined the MGA interval from the Ap index as being from DOY 97, 2008 to DOY 95, 2010, with a deep minimum starting around the middle of 2009. Solar wind speed and Ap index 27-day averages have minima near the end of 2009/beginning of 2010 (see also Emery et al., 2011). For reference, solar sunspot minimum occurred in
December 2008 (see http://www.swpc.noaa.gov/SolarCycle/ index.html).

Figure 1 presents the daily averaged VTEC values in 2008-2009. The top three panels show dayside (12:00 to 14:00 LT) low-latitude (from $-30^{\circ}$ to $30^{\circ}$ ) VTEC (panel a), the northern middle latitude (from $40^{\circ}$ to $60^{\circ}$ ) VTEC (panel b), and the southern middle latitude (from $-55^{\circ}$ to $-35^{\circ}$ ) VTEC (panel c) values. We chose somewhat lower latitude range for the Southern Hemisphere compared to the Northern Hemisphere to have similar data volumes (ground GPS coverage is poorer in subauroral southern latitudes). The near-midnight (22:00 to 24:00 LT) VTEC values for the Northern Hemisphere for low latitudes (from $-30^{\circ}$ to $30^{\circ}$ ) and middle latitudes (from $40^{\circ}$ to $60^{\circ}$ ) are given in the panels (d) and (e), respectively. Latitudes are given in solar magnetic coordinates. Gray shading indicates standard deviations of the daily values. VTEC is shown in TEC units, where TECU $=10^{12} \mathrm{el} \mathrm{cm}^{-2}$. The solar wind speed is shown in the panel (f) and the geomagnetic Ap index in the bottom panel. The data (panels $\mathrm{f}-\mathrm{g}$ ) are taken from the OMNI database (with $5 \mathrm{~min}$ data cadence). Vertical magenta lines indicate several peaks in daytime low-latitude TEC (panel a) which correspond to the solar wind speed and Ap increases (panels $f$ and $g$ ) to guide the eye.

We discuss the daytime ionospheric behavior first. The low-latitude range daytime VTEC (top panel, in black) is the highest among VTEC in all latitude ranges throughout two years (mostly due to contribution from equatorial ionization anomalies or EIAs) reaching 45 TECU for individual measurements. Daily averages range from $\sim 12$ to 33 TECU with the annual mean values around $\sim 20$ TECU. Daytime northern (panel b, in red) and southern (panel c, in cyan) midlatitude VTEC values are comparable to each other in magnitude, providing annual mean values of $\sim 10$ TECU. Results for the Northern Hemisphere are summarized in Table 1. Daytime data show pronounced semiannual variations with maxima around $\sim$ DOY $80-100$ and 280-300 for the lowlatitude daytime VTEC values (panel a, shown by wide black arrows) and for the middle-latitude daytime VTEC values (panel b, shown by wide red arrows). Corresponding semiannual maxima in the Southern Hemisphere daytime middlelatitude VTEC appear shifted from DOY 280-300 in 2008 and 2009 (panel c, shown by wide turquoise arrows). It has been suggested that semiannual peaks of Earth-based parameters are primarily controlled by the 13.5- and 27-day periodicities in the solar activity (due to solar rotation) and their peak values can change throughout a solar cycle with the minima being around the solar cycle minimum (Emery et al., 2011). Daily temporal variability in the vicinity of each ground GPS site as well as variability from one location to another (within the 2-h local time window) both contribute to the daily standard deviation parameter (shown by gray shading in the figure). This parameter is higher for low latitudes.

Nighttime low-latitude VTEC (around $\sim 8$ TECU) and its daily variability (or standard deviation of daily values) 


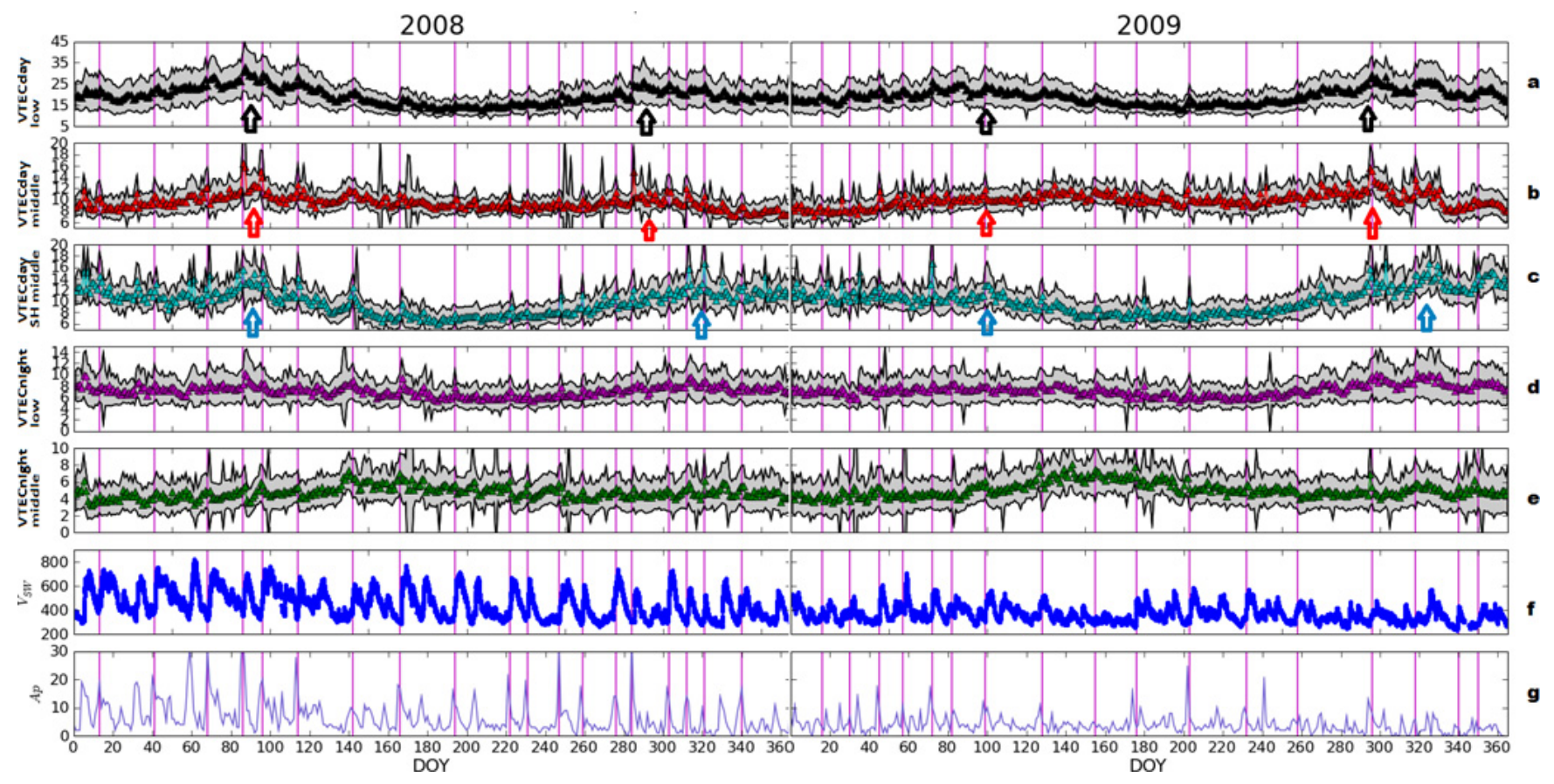

Fig. 1. Daily averaged VTEC values in 2008-2009 in different latitude and LT ranges: (a) low-latitude (from -30 to $30^{\circ}$ ), (b) northern middle latitude (from 40 to $60^{\circ}$ ), (c) southern middle latitude (from -55 to $-35^{\circ}$ ) ranges. Daytime values (panels a-c) correspond to VTEC values within the local time window 12:00 to 14:00 LT. Nighttime values for the Northern Hemisphere, near midnight (22:00 to 24:00 LT): (d) low-latitude (from -30 to $30^{\circ}$ ), (e) northern middle latitude (from 40 to $60^{\circ}$ ). Gray shading shows standard deviations of the daily values. Panels (f) and (g) show the solar wind speed at 1 AU and Ap index correspondingly (courtesy of the OMNI database at NASA/GSFC). Vertical thin magenta lines indicate selected peaks in daytime low-latitude TEC (panel a) which correspond to the solar wind speed and Ap increases (panels $\mathbf{f}$ and $\mathbf{g}$ ). The semiannual maxima in the panels (a)-(c) are indicated by wide black, red and turquoise arrows around the equinoxes.

Table 1. Daily VTEC averages statistics for 2008 and 2009.

\begin{tabular}{|c|c|c|c|c|c|c|c|c|c|}
\hline \multirow{2}{*}{ Northern Hemisphere } & \multicolumn{3}{|c|}{2008} & \multicolumn{3}{|c|}{2009} & \multicolumn{3}{|c|}{2003 HSS event } \\
\hline & Min & Average & Max & Min & Average & Max & Min & Average & $\operatorname{Max}$ \\
\hline Low latitudes & 12.36 & 19.70 & 33.03 & 12.93 & 19.51 & 29.37 & 51.76 & 54.73 & 58.24 \\
\hline Middle latitudes & 7.16 & 9.60 & 16.42 & 7.09 & 9.79 & 15.05 & 19.89 & 24.82 & 29.46 \\
\hline
\end{tabular}

(panel d, in magenta) are somewhat higher than the nighttime middle-latitude VTEC (around 4 TECU, panel e, in green). It is difficult to identify the semiannual variations in nighttime VTEC. There are no visible peaks around the equinoxes in panels (d) and (e). Note that at the solstices ( $\sim$ DOY 173 and 356) the daytime VTEC values (panels a and b) are comparable, or even slightly less than the nighttime values (panels $\mathrm{d}$ and e, correspondingly).

From Fig. 1f one can notice a continuous sequence of HSSs in 2008 with the solar wind speeds exceeding $\sim 600 \mathrm{~km} \mathrm{~s}^{-1}$. HSSs slightly diminish in magnitude by the middle of 2009 (in the middle of MGA). The Ap values increase during HSSs. Note a peak-to-peak correspondence for the average VTEC (central curves) in panels (a), (b), (c), solar wind speed increase in panel (f) and geomagnetic activity in panel (g) (shown by vertical magenta lines) on days $\sim 14$,
$40,70,90,110,170,190,220,230,240,250,260,280,310$, 320 and 340 in 2008 and $\sim 16,30,45,70,80,100,130,155$, 200, 230, 260, 300, 340 and 350 in 2009. This indicates a daytime low- and middle-latitude VTEC modulation of the averaged values possibly associated with HSSs. The correlation is less pronounced in the middle 2009 than in 2008 because of smaller HSSs and smaller disturbances in VTEC. Note that peaks in the gray-shaded areas indicate larger standard deviation in daily values and not the average trend. On the other hand, it is more difficult to determine if HSS events have observable effects on the nighttime VTEC. For instance, at day $\sim 70,2008$ we observe increases in nighttime VTEC during a HSS event, but decreases at day $\sim 60,2008$.

From Fig. 1 one can also see that geomagnetic activity and HSS occurrences are diminished in 2009 in comparison to 2008. The first part of 2009 (within the MGA 


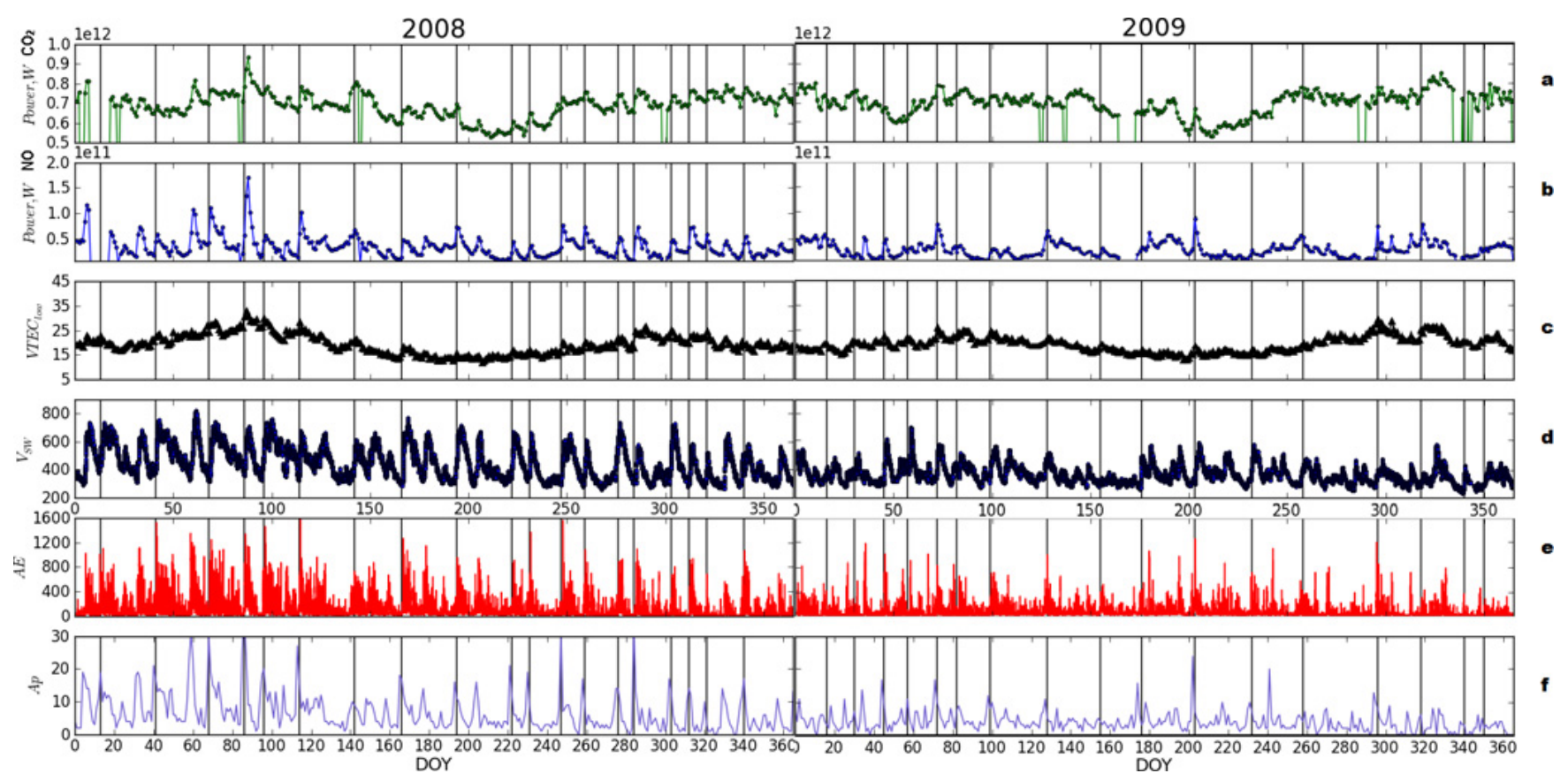

Fig. 2. Selected parameters for 2008-2009: (a) and (b) show global power of infrared $\mathrm{CO}_{2}$ and $\mathrm{NO}$ molecular line emissions; (c) daytime low-latitude VTEC, (d) solar wind speed, (e) AE index and (f) Ap index.

interval) is characterized by extremely low levels of Ap (mostly less than 10 units) and corresponding VTEC values are nearly constant, with average daytime low-latitude VTEC $\sim 19.1$ TECU and maximum $\sim 26.3$ TECU. For comparison the corresponding values in 2008 (solar cycle minimum) are 19.7 and 33.03 TECU (Table 1). By comparing years 2008 and 2009 it is found that the overall magnitudes of daytime VTEC are lower during the MGA interval in 2009 (up to $\sim 260$ DOY) than during solar minimum in 2008 for the same season. However, the annual VTEC means are similar. Figure 1 indicates that ionospheric daily variability (daily standard deviation) was almost suppressed during the beginning and middle of 2009. Except for an active region in March 2008 during the Whole Heliospheric Interval (WHI), from 20 March to 16 April 2008, the Sun was very quiet with F10.7 and $R_{\mathrm{X}}$ having very low values (around 70 and 10, correspondingly) and not showing much variability (not shown here to save space).

Geomagnetic activity during storms is often described by the Dst index, which is a quantitative measure of disturbances in the Earth's magnetic field derived from measurements at several middle-latitude geomagnetic observatories. In this paper we use the SYM-H index, a high-resolution ( $1 \mathrm{~min}$ ) measure of disturbances in the symmetric ring current, which is essentially the same as the Dst index (Mayaud, 1980; Wanliss and Showalter, 2006). The ASY-H index (Sugiura and Chapman, 1960) is a proxy for auroral-related activity and describes the partial ring current asymmetry during geomagnetically disturbed conditions.
Figure 2 repeats the daytime low-latitude VTEC in panel (c) and shows solar wind speed (panel d), and the $\mathrm{AE}$ and Ap indices (panels e and f). Vertical black lines correspond to sample events from Fig. 1. Activity indices show continuous medium to low geomagnetic activity coinciding with the leading edges of the HSSs or CIRs. Several examples for 2008 are around DOY 60, 90, 110, 170, 250, 280 and 340 with maximum $\mathrm{AE} \sim 1200$ and several peaks at $\mathrm{AE} \sim 1600$. Minimum SYM-H value was $\sim-50 \mathrm{nT}$. Continuously elevated AE indices indicate auroral activity in the form of HILDCAAs (Tsurutani and Gonzalez, 1987) with maximum values at the leading/peak edges of HSSs (or at CIRs) (Tsurutani et al., 2004a). In the MGA interval of 2009 we observe maximum AE values decrease to $\sim 800$ to 1200 (especially around DOY 100 to 170). Minimum SYM$\mathrm{H}$ increased to $\sim-30 \mathrm{nT}$. We will investigate further if the CIR/HSS- driven activity causes changes in global VTEC.

Figure 2a and b show global power of infrared $\mathrm{CO}_{2}$ and NO molecular line emissions. The values shown are daily averages over the globe derived from SABER measurements onboard the TIMED satellite (Mlynczak et al., 2010a). One can notice a weak semiannual dependence in $\mathrm{CO}_{2}$ emission power with decreases around $\sim$ DOY 200 (see a detailed multi-year analysis in Mlynczak et al., 2008; Hunt et al., 2011) which may be related to solar rotational periodicities (see Emery et al., 2011). No such anomaly is evident in NO emission power. A careful examination shows a correspondence between larger peaks in NO emission, small features in daily low-latitude VTEC, onsets of HSSs (solar wind speed) 
Table 2. Correlation between VTEC and NO emission power with Ap index and solar wind speed in 2008-2009. See text for details.

\begin{tabular}{|c|c|c|c|c|c|}
\hline 2008 & all Ap & $\begin{array}{l}\text { all Ap and } \\
\text { filtered series }\end{array}$ & $\begin{array}{l}\text { Ap }>15 \text { and } \\
\text { filtered series }\end{array}$ & $V_{\mathrm{sw}}>=500 \mathrm{~km} \mathrm{~s}^{-1}$ & $\begin{array}{c}V_{\mathrm{sw}}>=500 \mathrm{~km} \mathrm{~s}^{-1} \\
\text { and filtered series }\end{array}$ \\
\hline Low-latitudes $\mathrm{N}$ daytime & 0.54 & 0.49 & 0.81 & 0.41 & 0.91 \\
\hline Mid-latitudes N daytime & 0.51 & 0.47 & 0.68 & 0.491 & 0.83 \\
\hline Mid-latitudes S daytime & 0.49 & 0.49 & 0.78 & 0.35 & 0.87 \\
\hline Low-latitudes $\mathrm{N}$ nighttime & 0.61 & 0.43 & 0.83 & 0.46 & 0.91 \\
\hline Mid-latitudes $\mathrm{N}$ nighttime & 0.27 & 0.50 & 0.65 & 0.08 & 0.82 \\
\hline NO power & 0.19 & 0.12 & 0.61 & 0.20 & -0.02 \\
\hline \multicolumn{6}{|l|}{2009} \\
\hline Low-latitudes $\mathrm{N}$ daytime & 0.54 & 0.73 & 0.71 & 0.145 & 0.91 \\
\hline Mid-latitudes N daytime & 0.51 & 0.62 & 0.94 & 0.29 & 0.83 \\
\hline Mid-latitudes S daytime & 0.49 & 0.60 & 0.66 & 0.11 & 0.87 \\
\hline Low-latitudes $\mathrm{N}$ nighttime & 0.61 & 0.68 & 0.98 & 0.09 & 0.90 \\
\hline Mid-latitudes $\mathrm{N}$ nighttime & 0.27 & 0.56 & 0.90 & 0.14 & 0.78 \\
\hline NO power & 0.19 & 0.51 & 0.86 & 0.18 & -0.04 \\
\hline
\end{tabular}

and level of geomagnetic activity in Ap. Several examples of this relationship are indicated by vertical black lines (repeated from Fig. 1). The annual estimate of global NO infrared emission for the solar minimum year 2008 and the MGA year 2009 are $3.3 \times 10^{10} \mathrm{~W}$ and $2.7 \times 10^{10} \mathrm{~W}$, respectively.

Next we consider daily averaged ionospheric VTEC during one of well-studied HSS intervals: 10-22 October 2003 or Event 1 in Tsurutani et al. (2011b). Figure 3 has the same format as Fig. 1. The storm main phase onset around $\sim$ DOY 286.5 was caused by the arrival and impingement of a CIR onto the magnetosphere. The maximum Ap reached $\sim 70$. Starting at DOY 288 , a pure HSS with the peak velocity $\sim 770 \mathrm{~km} \mathrm{~s}^{-1}$ was observed. HILDCAA events occur during the storm recovery phase (Tsurutani et al., 2011b). Average daytime low-latitude and middle-latitude VTEC values during the 2003 event were $\sim 54.7$ and 24.82 TECU, correspondingly. Because of large standard deviations, it is difficult to determine when a maximum value was reached.

By comparing HSS events occurring at the onset of the declining phase of SC23 (Fig. 3), and the late declining phase and the solar minimum (Fig. 1) one can conclude that the daytime daily VTEC and its standard deviation (the width of the gray ribbon) within a day especially in low latitudes is much higher in 2003 than in 2008-2009. Table 1 summarizes that the event-averaged daytime low-latitude VTEC in 2003 is $\sim 55 \mathrm{TECU}$ (maximum value up to $\sim 58 \mathrm{TECU}$ ) compared to 20 TECU in 2008-2009. The nighttime low-latitude VTEC was somewhat higher and more variable in 2003 than in 2008-2009, whereas nighttime mid-latitude VTEC was about the same. Since only one HSS occurred during the 2003 event (Fig. 3f) it is difficult to compare day-to-day variability. Annual average values of F10.7 were $\sim 69$ and 71 in 2008 and 2009, correspondingly. In comparison F10.7 averaged over the 2003 event is $\sim 112.5$. The event-averaged
NO emission power for the event was $\sim 2.0 \times 10^{11} \mathrm{~W}$. Thus, the annual estimate of NO infrared emission for 2008-2009 is decreased by $\sim 85 \%$ in comparison to 2003 . The level of auroral activity during the 2003 interval (Fig. 3g) was somewhat higher (Ap was up to 70) than in 2008-2009 (Ap was up to $\sim 30$ ). The minimum SYM-H was $\sim-80 \mathrm{nT}$ during the 2003 event.

To quantify HSS effects of the average daily VTEC we estimated the correlation of VTEC in different latitude and local time ranges (the panels a-e of Fig. 1) with Ap index and solar wind speed in 2008 and 2009 separately. The results are shown in Table 2. The VTEC and Ap index (2nd column) show modest correlations for daytime VTEC values (up to $54 \%$ ) and $\sim 61 \%$ for low-latitude nighttime VTEC. To isolate a component in the VTEC series with a temporal behavior similar to the Ap index we applied standard digital filtering with the filter coefficients calculated from the Ap series. After a convolution with the filter, we estimate an Ap-like component in VTEC data which we refer as to the filtered VTEC. Such a procedure is similar to applying the Fourier transform to study a certain wave harmonic. Correlation between Ap and the filtered VTEC did not improve the results much (3rd column) and this shows a weak signal in noisy data. Then we cut off the quiet-time background with Ap $<15$ and the resultant correlation coefficients (shown in red in the 4th column) showed a strong presence of Ap-like signal during moderately disturbed conditions. Alternatively, if we impose a solar wind velocity threshold of $500 \mathrm{~km} \mathrm{~s}^{-1}$ and calculate the correlation with the filtered VTEC (last column, in red), again there is a correlation between HSSs and filtered VTEC. It is interesting to note that there is no clear dependence of the correlation coefficients with filtered VTEC during disturbed intervals on local time or latitude range. However, we are cautious about the reliability of the nighttime VTEC results since the values are smaller than 


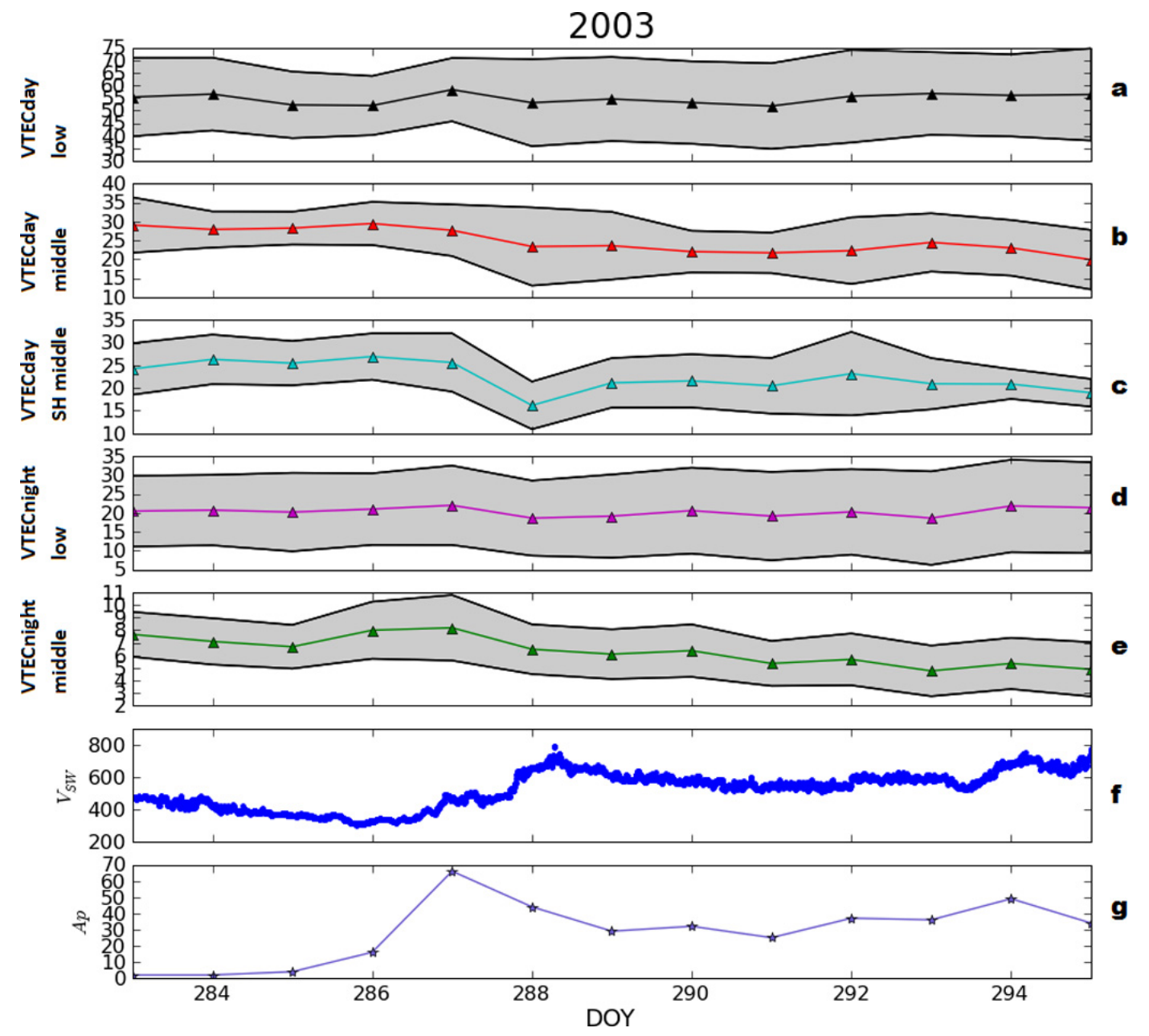

Fig. 3. The same format as in Fig. 1 but for the 2003 HSS event 1: 10-22 October 2003.

daytime values but have about the same standard deviations, i.e., the nighttime average data are noisy.

Filtered NO emission power (Fig. 2, panel b) shows $61 \%$ and $86 \%$ correlations with Ap during moderately disturbed intervals $(\mathrm{Ap}>15)$ in 2008 and 2009, correspondingly. There is a poor correlation with the solar wind speed. It is known that the NO emission power peaks during the CIR phase of CIR-type storms which occur before the HSS proper (Mlynczak et al., 2010b; Verkhoglyadova et al., 2011). Thus, it is reasonable to assume that this parameter should relate to an activity index increase rather than an increase in the solar wind speed. We speculate that a higher correlation with activity index in 2009 than in 2008 can be due to the absence of moderate flares and very flat F10.7 (see Fig. 2 of Hunt et al., 2011) in 2009. Thus, thermospheric heating and cooling in 2009 could be almost solely determined by the geomagnetic activity.

\section{Discussion}

The behavior and variability of daily ionospheric VTEC values due to HSSs during 2008 and 2009 has been examined in this paper. Next we will discuss the roles of the disturbance dynamo (DD) induced by Joule heating and prompt penetrating electric field (PPEF) mechanisms in VTEC increases during HSS events. Tsurutani et al. (2006b) proposed that HILDCAA events cause high-latitude heating and corresponding disturbance dynamo effects which in turn affect high-latitude VTEC intensities. High-latitude thermospheric heating in response to different polarity of IMF Bz has been extensively studied by McHarg et al. (2005). They concluded that hemispherically integrated Joule heating increases dramatically in the post-midnight sector of the auroral zone during southward IMF intervals. This result, even though the authors did not separate ICME and CIR events, supports the above suggestion of efficient generation of disturbance dynamos during HSS events. The physical mechanism is the extended Alfvénic wave trains within the HSSs and explains the VTEC 
Table 3. Correlation between interplanetary parameters and activity indices in 2008-2009.

\begin{tabular}{ccccc}
\hline & $V_{\mathrm{sw}}-E_{\mathrm{y}}$ & $-\mathrm{SYM}-\mathrm{H}-V_{\mathrm{Sw}}$ & $-\mathrm{SYM}-\mathrm{H}-E_{\mathrm{y}}$ & ASY-H- $E_{\mathrm{y}}$ \\
\hline 2008 & 0.980 & -0.103 & -0.104 & -0.424 \\
2009 & 0.981 & -0.045 & -0.045 & -0.305 \\
\hline
\end{tabular}

increases in auroral and slightly subauroral regions. Based on radar measurements of ionospheric temperatures, Sojka et al. (2009) have shown that CIRs drive ionospheric heating in the northern polar and auroral regions. In a modeling study by Lu et al. (2010), Joule heating/dissipation is shown to be responsible for the enhanced thermospheric radiative emission by NO during geomagnetic disturbances. On the other hand, the disturbance dynamo mechanism does not account for the fast response (within $\sim 1 \mathrm{~h}$ ) of VTEC enhancements in low- to middle-latitudes noted during CIR/HSS events (Verkhoglyadova et al., 2011). Koga et al. (2011) showed a prompt (about $1 \mathrm{~h}$ ) ionospheric response in the displacement of the equatorial F-peak height during a HILDCAA event.

Tsurutani et al. (2006b) and Verkhoglyadova et al. (2011) suggested that during HSS events moderate intensity interplanetary electric fields (IEFs) penetrate into low- to middlelatitude ionosphere, causing increases in daytime VTEC. The PPEF mechanism was originally invoked to explain extreme dayside VTEC increases and ionosphere uplifts during large geomagnetic storms around solar maximum (Tsurutani et al., 2004b, 2008; Mannucci et al., 2005; Verkhoglyadova et al., $2006,2008)$. Kelley et al. $(1979,2003)$ first noted similar occurrences with substorms. According to this mechanism, the IEF $E_{\mathrm{y}}$ component, if directed in a dawn-to-dusk direction, can cause a dayside ionospheric uplift. Figure 4 shows this geoeffective component (as positive values) together with the solar wind speed and SYM-H index for 2008-2009. The convection IEF $E_{\mathrm{y}}$ is calculated with the solar wind flow velocity and the IMF (taken from the OMNI database). Note a general decline in the speed magnitude, magnetic storm intensity and $E_{\mathrm{y}}$ magnitude from $\sim 4-6 \mathrm{mV} \mathrm{m}^{-1}$ to $\sim 2 \mathrm{mV} \mathrm{m}^{-1}$ throughout the interval from 2008 to 2009 . There is a correspondence between peaks in $E_{\mathrm{y}}$ and HSS occurrences in Fig. 4, seen for example for days $\sim 5,30,40,60,110,120,170$, 220, 230, 250, 300 and 340 in 2008 and $\sim 30,45,70,100$, $180,200,230$ and 320 in 2009. The correlation coefficient between the geoeffective IEF component and the solar wind speed is $\sim 98 \%$ for both years (Table 3). By definition this result indicates a high occurrence of geoeffective IEF component when the solar wind speed is high. Thus, there is a possibility of efficient driving of the low- to middle-latitude ionosphere by HSSs through moderate PPEFs. Another explanation is that electric field and current perturbations cause increases in magnetospheric convection and move the nighttime shielding layer equatorward, causing temporary undershielding and dawn-dusk middle- and low-latitude electric fields (see a review by Fejer, 2011). We would like to note that PPEF effects are LT dependent, with southward IMF Bz causing geoeffective eastward ionospheric electric fields on the dayside and westward on the nightside (Tsurutani et al, 2004b, 2008). Thus, global VTEC averaging without LT separation (Lei et al., 2008) may not reveal PPEF effects.

The SYM-H index during CIR-type storms is highly variable with the minima lined up with leading peaks in the solar wind speed (CIRs), maximum AE indices, and Ap peaks. However, a general correlation between the solar wind speed and SYM-H in 2008-2009 is low (Table 3, Fig. 4). This result may indicate moderate and irregular (possibly nonlinear) ring current responses to southward IMF Bz throughout the "recovery" of the CIR storms or HSS proper. Soraas et al. (2004) observed sporadic night-side particle injection into outer shells $L>4$ during HSS events. No injection to deeper shells was observed.

There is no correlation between SYM-H and IMF $E_{\mathrm{y}}$ (Table 3). However, there is a higher anti-correlation with ASY$\mathrm{H}$ index (Table 3, last column). According to Sugiura and Chapman (1960), the partial ring current is most asymmetric in the main phase of a geomagnetic storm and becomes increasingly symmetric during the recovery phase. Thus, it is possible that this correlation captures a relationship between main phase of the CIR storm and IMF $E_{\mathrm{y}}$.

HSSs proper (trailing CIRs) are associated with HILDCAAs which cause heating of the auroral ionosphere and particle precipitation. Previous studies (see a review in Tsurutani et al., 2004a) have indicated a high correlation between southward IMF $B_{\mathrm{Z}}$ in interplanetary Alfvénic wave trains and AE indices throughout the whole HSS intervals, which can be interpreted by efficient energy influx into the magnetosphere and auroral ionosphere during reconnection events. Analysis of Polar UVI images during HSS intervals has shown moderate auroral activity at all local times, which can spread up to the polar cap and last up to weeks (Guarnieri, 2006). Thus, high-latitude energy deposition associated with HILDCAAs can cause efficient heating of the thermosphere (especially in auroral latitudes), onset of a DD and consequential cooling by the way of increased infrared emission. Mlynczak et al. (2003) proposed a mechanism of NO acting as an atmospheric thermostat during large magnetic storms. This mechanism can be responsible for the modulation of total infrared emission power by HSSs as well (Fig. 2, panels $b, d$ and f). A detailed study of ionospheric VTEC and thermospheric emission during WHI supports this assumption (Verkhoglyadova et al., 2011). Extensive modeling by Solomon et al. (2012) has shown that southward IMF $B_{\mathrm{Z}}$ is the most important factor in the thermospheric and ionospheric response to CIR and HSSs.

Recent TIE-GCM simulation results demonstrate the importance of the DD mechanism to capture the main features of zonal drifts at dawn and dusk during HSS events in 2005 (Pedatella and Forbes, 2011). On the other hand, both this modeling and observations of neutral density (Lei 

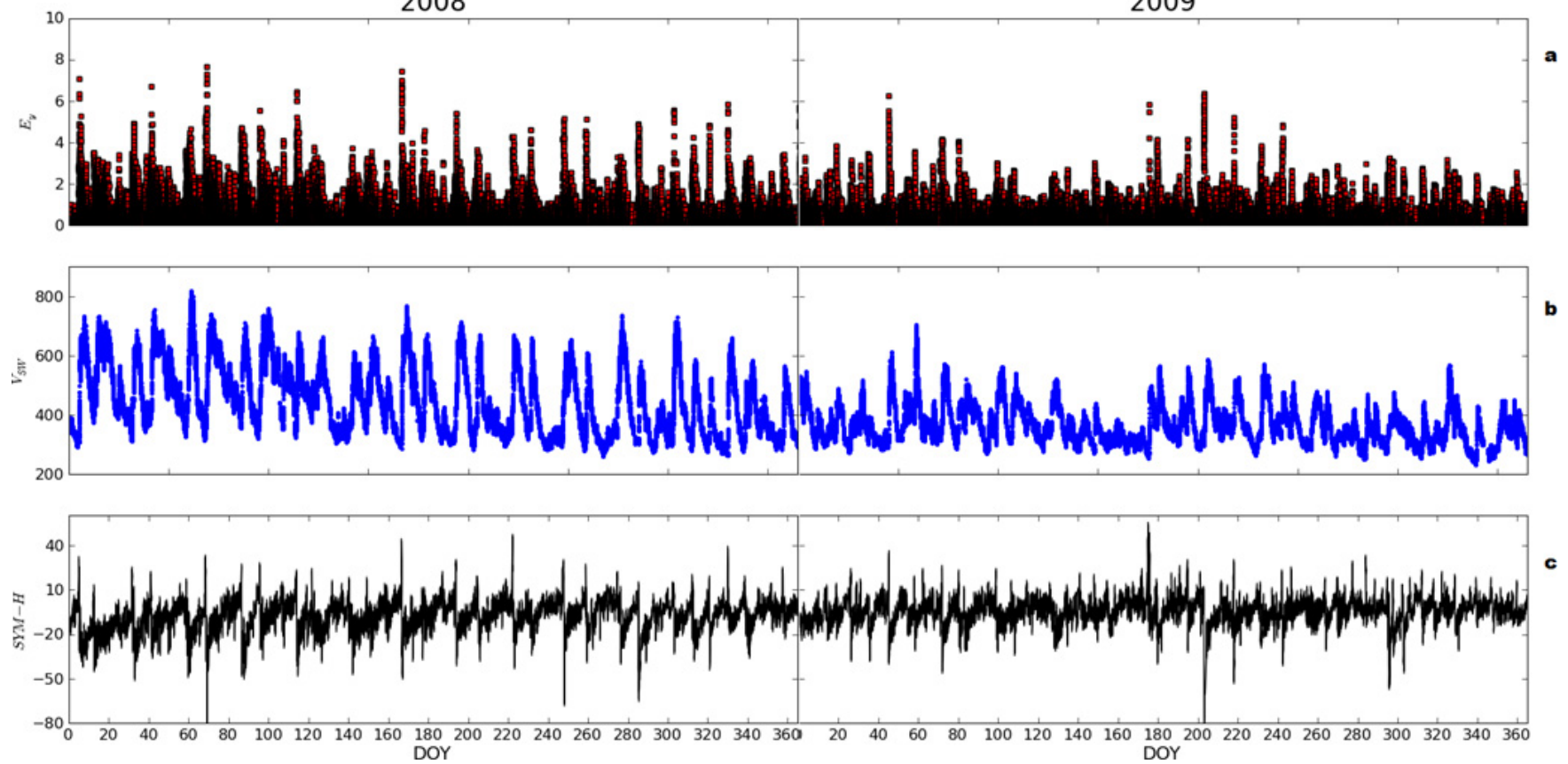

Fig. 4. Solar wind parameters for 2008-2009: (a) geoeffective IEF $E_{\mathrm{y}}$ (as positive value), (b) the solar wind speed and (c) SYM-H index. The convection IEF $E_{\mathrm{y}}$ is calculated with the solar wind flow velocity and IMF.

et al., 2011) have shown an $\sim 0.5$ to 1 day delay in response to external forcing. It has been suggested that this could be a global response time of the thermosphere to CIR forcing (Pedatella and Forbes, 2011). We propose that the DD mechanism is important to explain global thermospheric and ionospheric dynamics during long-duration and moderate forcing within CIR/HSS intervals by the way of direct energy transfer into the high-latitude ionosphere. However, it will take several hours to a day to take place. PPEFs can be responsible for more prompt response (up to several hours), especially in the low- to middle-latitude ionosphere, for example observed by Verkhoglyadova et al. (2011) for March-April 2008.

Figure 1 also shows larger responses in the $-30^{\circ}$ to $30^{\circ}$ latitude range than in the $40^{\circ}$ to $60^{\circ}$ range, which agrees with the PPEF mechanism. During large magnetic storms PPEF can penetrate into the ionosphere for hours (Huang et al., 2005). Observations during moderate geomagnetic activity indicate that penetration can take place for $\sim$ one hour (see Fejer, 2011, and references therein). Verkhoglyadova et al. (2011) estimated that geoeffective CIR/HSS can cause a moderate (up to 10 times lower than a superstorm) $E_{\mathrm{y}} \sim$ $5 \mathrm{mV} \mathrm{m}^{-1}$ with less than $\sim 1-2 \mathrm{~h}$ to create a response in the low-latitude ionosphere. Lai et al. (2011) provided an estimate of $<1 \mathrm{mV} \mathrm{m}^{-1}$ based on COSMIC observations of dayside VTEC. The HSS proper is highly variable and is characterized by low to moderate geomagnetic activity associated with HILDCAA, which continues for weeks. Koga et al. (2011) concluded that there is an efficient coupling of the IEF and the equatorial ionosphere during a HILDCAA event.
Wei et al. (2008) suggested that the interplanetary electric field (IEF) penetrates into the equatorial ionosphere during HILDCAA events via short-time $(<3 \mathrm{~h})$ dawn-dusk IEF pulses without shielding (see also Kelley et al., 2003, for details on the physical mechanism). We suggest that HILDCAA with extended Alfvénic wave trains and southward excursions of IMF $B_{\mathrm{z}}$ could drive observed global dayside VTEC (Fig. 1) by the PPEF mechanism especially at low-latitudes.

The auroras and current systems during HILDCAAs are different from other types of auroral activity. It was shown that AE increases in HILDCAAs and substorms are poorly correlated (Tsurutani et al., 2004a, 2006c), and can transfer large amounts of energy to the auroral region (Guarnieri, 2006), thus efficiently starting the DD. Low and equatorial ionosphere studies performed during HSS intervals have shown complex longitudinal dependence of DD electric fields (Abdu et al., 2006; Sobral et al., 2006; de Siqueira et al., 2011). The current understanding is that DD electric field effects on low-latitude ionosphere during HSS are LT dependent, moderate, long-lasting and can significantly modify the phenomenology of the ionosphere (inhibition of prereversal enhancement, plasma instability development, etc.). However, since DD and PPEF act in an opposite way it could be difficult to separate both effects in dayside observations. More observations are needed to reconstruct the complete picture of the ionospheric response in this case.

We would like to emphasize that in strictly physical terms, the bulk solar wind plasma flow (V) determines IEF with the MHD approximation of $E=\frac{1}{c}[V \times B]$, where $B$ is the IMF. 
Thus, our description of the ionospheric response to external forcing during magnetic storms in terms of electric fields is merely convenient and traditional. In actuality, storm-time electric fields are generated through disturbances in plasma flows which in turn are determined by stresses acting on plasma (Vasyliūnas, 2001, 2011; Tsurutani et al., 2008).

\section{Conclusions}

Ionospheric daily VTEC values averaged in several latitude ranges during 2008-2009 (solar cycle minimum and MGA interval) were studied. Daytime low- and middle-latitude VTEC values are highly variable during CIR-HSS intervals. We suggest that there is an ionospheric response caused by a moderate geomagnetic activity due to external forcing. There is a certain correlation between peaks in daytime average VTEC, HSS events and elevated geomagnetic activity (Fig. 1). There were nighttime ionospheric responses to the HSSs during 2008-2009, especially in the filtered VTEC data. However, we would like to note the high variability (standard deviation) and low "noise-to-signal ratio" in nighttime VTEC, which makes it difficult to reach definite conclusions.

During 2008 the daytime (12:00 to 14:00 LT) lowlatitude VTEC reached up to 33 TECU (annual average of $\sim 20 \mathrm{TECU})$. The maximum VTEC value was $\sim 30 \mathrm{TECU}$ during the MGA interval of 2009. Averages of annual daily VTEC in 2008 and 2009 are similar, with the corresponding values being slightly lower in 2009 (Table 1). This may be due to inclusion of the deep MGA interval (a decline in geomagnetic activity) and onset of the next solar cycle (a rise in EUV flux) in 2009. Our results show different levels of ionospheric variability in 2008 and 2009. This effect could be related to the decline in HSS magnitudes and the deep minimum in geomagnetic activity in 2009 studied by Tsurutani et al. (2011a).

A well-studied solar cycle declining phase interval, 1022 October 2003 (Fig. 3), was also analyzed. The maximum VTEC value during this interval (a single HSS) was up to $\sim 60$ TECU (event average of $\sim 55$ TECU). Thus, ionospheric VTEC during 2008-2009 was $\sim 60 \%$ less on average. To estimate ionospheric response to external driving we calculated the difference between maximum and minimum daily averaged VTEC and normalized it by the average value. During the 2003 event, the response was only $\sim 14 \%$ (8 TECU change), whereas the response during 2008-2009 (multiple HSSs) was $\sim 90 \%$ (18 TECU) change in VTEC. However, we cannot attribute this variability to HSSs alone. It is noted that solar EUV radiation was different during these intervals. It declined from the event-averaged F10.7 value of $\sim 110$ in 2003 to the annual average of $\sim 70$ in $2008-2009$. Further study is needed to provide enough statistics for comparison between ionospheric responses to HSS during different phases of the solar cycle.
We have noted larger values (compare Figs. 1 and 3) and daily data spread (gray-shaded regions) for the 2003 event compared to the HSS intervals in 2008-2009. The 2003 event was also more geoeffective (minimum SYM-H $\sim-80 \mathrm{nT}$ ) than events in the late declining phase and the solar minimum (SYM-H $\sim-50$ to $-30 \mathrm{nT}$, see Fig. 4). STEREO observations showed that low-latitude coronal holes predominant for a declining phase of the solar cycle started to "close down" and disappear by 2009 (de Toma, 2011). Thus, the early declining phase of 2003 and the late declining phase of 2008 (and the solar minimum of 2009) had remarkably different solar conditions (see also Echer et al., 2011; Tsurutani et al., 2011a). This effect can be responsible for different ionospheric responses during HSS intervals in the solar and geomagnetic minima.

Clear semiannual variation is seen in the daytime VTEC (Fig. 1). It is tempting to associate the maxima with the equinoxes (Lal, 1998; Zhao et al., 2007; Lai et al., 2011). However, the equinoxes occurred on $\sim$ DOY 80 and 266, where the second date does not correspond to observed peaks. Moreover, the semiannual peaks in daytime low- and southern hemispheric middle-latitude VTEC (panels a and c) are shifted in relation to each other. The location and magnitude of the semiannual peaks could be due to changing amplitudes in 13.5- and 27-day solar rotational periodicities that were shown to affect energy transfer down to the Earth (Emery et al., 2011). Detailed study of this phenomenon is beyond the scope of this paper.

We used the daily averaged thermospheric NO emission power derived from SABER/TIMED measurements as a proxy for the radiation balance of the thermosphere. This event-averaged power was $\sim 2.0 \times 10^{11} \mathrm{~W}$ for the 2003 event (Fig. 2). The annual estimate of NO infrared emission for the solar minimum year 2008 and the MGA year 2009 is decreased by $\sim 85 \%$ in comparison to 2003 . The solar cycle dependence of the thermosphere radiation balance and onset of the SC24 are discussed in Mlynczak et al. (2007, 2010a) and Hunt et al. (2011). We note variability in NO emission in connection with moderate geomagnetic activity during CIR/HSSs (Mlynczak et al., 2010b; Verkhoglyadova et al., 2011). Increased auroral energy input for HSS proper (reflected in AE indices) and associated heating are likely driven by HILDCAAs.

To understand the mechanism of the solar windionosphere coupling during HSSs we analyzed the role of the prompt penetrating electric field (PPEF) mechanism. There is a correlation between geoeffective IEF intervals and HSS occurrences (Fig. 4), and daytime VTEC variability (Figs. 1, 3). It is plausible to suggest that the PPEF is responsible for a prompt (within several hours) ionospheric response during a CIR/HSS interval. HILDCAAs associated with HSSs can cause large and long-duration energy input into polar and auroral regions. This suggestion is in agreement with a large body of previous studies on low-latitude ionospheric response to moderate geomagnetic storms (Fejer, 
2011). There is evidence of prompt equatorial ionospheric response and continuously penetrating IEF (Wei et al., 2008; Koga et al., 2011) during HILDCAAs. On the other hand, both PPEFs and DDs could contribute to a combined ionosphere/thermosphere response during a long "recovery" HSS phase several hours after the event onset.

It should be noted by the reader that we did not consider other possible mechanisms of the ionosphere-thermosphere coupling during prolonged moderate geomagnetic activity in this study. Mechanisms involving neutral composition changes and disturbance winds can also cause variations of TEC during such activity intervals. To decide between possible mechanisms, a study with a higher temporal (hours) and spatial resolution is needed. Our goal was to show the external driving of TEC variability during a solar sunspot minimum interval and the relationship between CIR-HSSs features and global daily ionospheric and thermospheric responses.

Acknowledgements. Portions of this work were done at the Jet Propulsion Laboratory, California Institute of Technology, under contract with NASA. MGM would like to acknowledge support from the NASA TIMED project office. The authors would like to thank referees for very valuable suggestions.

Topical Editor K. Kauristie thanks B. Emery and one anonymous referee for their help in evaluating this paper.

\section{References}

Abdu, M. A., de Souza, J. R., Sobral, J. H. A., and Batista, I. S.: Magnetic storm associated disturbance dynamo effects in the low and equatorial latitude ionosphere, in: Recurrent Magnetic Storms: Corotating Solar Wind Streams, Geophys. Monogr., vol. 167, edited by: Tsurutani, B. T., McPherron, R. L., Gonzalez, W. D., Lu, G., Sobral, J. H. A., and Gopalswamy, N., p. 283, Am. Geophys. Univ. Press, Washington D.C., 2006.

Burns, A. G., Solomon, S. C., Qian, L., Wang, W., Emery, B. A., Wiltberger, M., Weimer, D. R.: The effects of Corotating interaction region/High speed stream storms on the thermosphere and ionosphere during the last solar minimum, J. Atmos. Solar Terr. Phys., 83, 79-87, doi:10.1016/j.jastp.2012.02.006, 2012.

Crowley, G., Reynolds, A., Thayer, J. P., Lei, J., Paxton, L. J., Christensen, A. B., Zhang, Y., Meier, R. R., and Strickland, D. J.: Periodic modulations in thermospheric composition by solar wind high speed streams, Geophys. Res. Lett., 35, L21106, doi:10.1029/2008GL035745, 2008.

de Siqueira, P. M., de Paula, E. R., Muella, M. T. A. H., Rezende, L. F. C., Abdu, M. A., and Gonzalez, W. D.: Storm-time total electron content and its response to penetration electric fields over South America, Ann. Geophys., 29, 1765-1778, doi:10.5194/angeo-29-1765-2011, 2011.

de Toma, G.: Evolution of Coronal Holes and Implications for HighSpeed Solar Wind During the Minimum Between Cycles 23 and 24, Solar Phys., 274, 195-217, doi:10.1007/s11207-010-9677-2, 2011.

Echer, E., Tsurutani, B. T., Gonzalez, W. D., and Kozyra, J. U.: High Speed Stream Properties and Related Geomagnetic Activity during the Whole Heliosphere Interval (WHI): 20 March to 16 April 2008, Solar Phys., doi:10.1007/s11207-011-9739-0, 2011.

Emery, B. A., Richardson, I. G., Evans, D. S., and Rich, F. J.: Solar wind structure sources and periodicities of auroral electron power over three solar cycles, J. Atmos. Solar Terr. Phys., 71, 1157-1175, 2009.

Emery, B. A., Richardson, I. G., Evans, D. S., Rich, F. J., and Wilson, G. R.: Solar rotational periodicities and the semiannual variation in the solar wind, radiation belt, and aurora, Solar Phys., 274, 399-425, doi:10.1007/s11207-011-9758-x, 2011.

Fejer, B. G.: Low latitude ionospheric electrodynamics, Space Sci. Rev., 158, 145-166, doi:10.1007/s11214-010-9690-7, 2011.

Gibson, S. E., Kozyra, J. U., de Toma, G., Emery, B. A., Onsager, T., and Thompson, B. J.: If the Sun is so quiet, why is the Earth ringing? A comparison of two solar minimum intervals, J. Geophys. Res., 114, A09105, doi:10.1029/2009JA014342, 2009.

Guarnieri, F. L.: The nature of auroras during high-intensity longduration continuous AE activity (HILDCAA) events, 1998 to 2001, in: Recurrent Magnetic Storms: Corotating Solar Wind Streams, Geophys. Monogr., vol. 167, edited by: Tsurutani, B. T., McPherron, R. L., Gonzalez, W. D., Lu, G., Sobral, J. H. A., and Gopalswamy, N., p. 235, Am. Geophys. Univ. Press, Washington D.C., 2006.

Huang, C.-S., Foster, J. C., and Kelley, M. C.: Long-duration penetration of the interplanetary electric field to the low-latitude ionosphere during the main phase of magnetic storms, J. Geophys. Res., 110, A11309, doi:10.1029/2005JA011202, 2005.

Huang, Y., Deng, Y., Lei, J., Ridley, A., Lopez, R., Allen, R. C., and McButler, B.: Comparison of Joule heating associated with high-speed solar wind between different models and observations, J. Atmos. Solar Terr. Phys., 75-76, 5-14, doi:10.1016/j.jastp.2011.05.013, 2012.

Hunt, L. A., Mlynczak, M. G., Marshall, B. T., Mertens, C. J., Mast, J. C., Thompson, R. E., Gordley, L. L., and Russell III, J. M.: Infrared radiation in the thermosphere at the onset of solar cycle 24, Geophys. Res. Lett., 38, L15802, doi:10.1029/2011GL048061, 2011.

Kelley, M. C., Fejer, B. G., and Gonzales, C. A.: An explanation for anomalous ionospheric electric field associated with a northward turning of the interplanetary magnetic field, Geophys. Res. Lett., 6, 301-304, 1979.

Kelley, M. C., Makela, J. J., Chau, J. L., and Nicolls, M. J.: Penetration of the solar wind electric field into the magnetosphere/ionosphere system, Geophys. Res. Lett., 30, 1158-1160, doi:10.1029/2002GL016321, 2003.

Knecht, D. J. and Shuman, B. M.: The geomagnetic field, in: Handbook Of Geophysics and the Space Environment, edited by: Jursa, A. S., p. 4-1, Air Force Geophys. Lab., Bedford, Mass., 1985.

Knipp, D. J., Tobiska, W. K., and Emery, B. A.: Direct and indirect thermospheric heating sources for solar cycles 21-23, Solar Phys., 224, 495-505, 2004.

Knipp, D., Eriksson, S., Kilcommons, L., Crowley, G., Lei, J., Hairston, M., and Drake, K.: Extreme Poynting flux in the dayside thermosphere: Examples and statistics, Geophys. Res. Lett., 38, L16102, doi:10.1029/2011GL048302, 2011.

Koga, D., Sobral, J. H. A., Gonzalez, W. D., Arruda, D. C. S., Abdu, M. A., deCastilho, V. M., Mascarenhas, M., Gonzalez, A. C., Tsurutani, B. T., Denardini, C. M., and Zamlutti, C. J.: Electro- 
dynamic coupling processes between the magnetosphere and the equatorial ionosphere during a 5-day HILDCAA event, J. Atmos. Solar Terr. Phys., 73, 148-155, 2011.

Kozyra, J. U., Crowley, G., Emery, B. A., Fang, X., Maris, G., Mlynczak, M. G., Niciejewski, R. J., Palo, S. E., Paxton, L. J., and Randall, C. E.: Response of the Upper/Middle Atmosphere to Coronal Holes and Powerful High-Speed Solar Wind Streams in 2003, in: Recurrent Magnetic Storms: Corotating Solar Wind Streams, Geophys. Monogr., vol. 167, edited by: Tsurutani, B. T., McPherron, R. L., Gonzalez, W. D., Lu, G., Sobral, J. H. A., and Gopalswamy, N., p. 319, Am. Geophys. Univ. Press, Washington D.C., 2006.

Lai, P.-C., Lin, C. S., Burke, W. J., Huang, C.-M., and Chen, M.-Q.: COSMIC observations of dayside total electron content enhancements in response to moderate disturbances in the solar wind, J. Geophys. Res., 116, A05318, doi:10.1029/2010JA015772, 2011.

Lal, C.: Solar wind and equinoctial maxima in geophysical phenomena, J. Atmos. Solar Terr. Phys., 60, 1017-1024, 1998.

Lei, J., Thayer, J. P., Forbes, J. M., Wu, Q., She, C., Wan, W., and Wang, W.: Ionosphere response to solar wind high-speed streams, Geophys. Res. Lett., 35, L19105, doi:10.1029/2008GL035208, 2008.

Lei, J., Thayer, J. P., Wang, W., and McPherron, R.: Impact of CIR Storms on Thermosphere Density Variability during the Solar Minimum of 2008, Solar Phys., 1, 427, doi:10.1007/s11207-0109563-y, 2011.

Liu, J., Liu, L., Zhao, B., Wan, W., and Heelis, R. A.: Response of the topside ionosphere to recurrent geomagnetic activity, J. Geophys. Res., 115, A12327, doi:10.1029/2010JA015810, 2010.

Lu, G., Mlynczak, M. G., Hunt, L. A., Woods, T. N., and Roble, R. G.: On the relationship of Joule heating and nitric oxide radiative cooling in the thermosphere, J. Geophys. Res., 115, A05306, doi:10.1029/2009JA014662, 2010.

Luhmann, J. G., Li, Y., Arge, C. N., Gazis, P. R., and Ulrich, R.: Solar cycle changes in coronal holes and space weather cycles, Geophys. Res., 107, A8, doi:10.1029/2001JA007550, 2002.

Mannucci, A. J., Wilson, B. D., Yuan, D. N., Ho, C. H., Lindqwister, U. J., and Runge, T. F.: A global mapping technique for GPSderived ionospheric total electron content measurements, Radio Sci., 33, 565-582, 1998.

Mannucci, A. J., Iijima, B., Sparks, L., Pi, X. Q., Wilson, B., and Lindqwister, U.: Assessment of global TEC mapping using a three-dimensional electron density model, J. Atmos. Solar-Terr. Phys., 61, 1227-1236, 1999.

Mannucci, A. J., Tsurutani, B. T., Iijima, B. A., Komjathy, A., Saito, A., Gonzalez, W. D., Guarnieri, F. L., Kozyra, J. U., and Skoug, R.: Dayside global ionospheric response to the major interplanetary events of October 29-30 2003 "Halloween storms", Geophys. Res. Lett., 32, L12S02, doi:10.1029/2004GL021467, 2005.

Marsh, D. R., Solomon, S. C., and Reynolds, A. E.: Empirical model of nitric oxide in the lower thermosphere, J. Geophys. Res., 109, A07301, doi:10.1029/2003JA010199, 2004.

Mayaud, P. N.: Derivation, Meaning, and Use of Geomagnetic Indices, in Geophysical Monograph 22, American Geophysical Union, Washington D.C., 1980.

McHarg, M., Chun, F., Knipp, D., Lu, G., Emery, B., and Ridley, A.: High-latitude Joule heating response to IMF inputs, J. Geophys. Res., 110, A08309, doi:10.1029/2004JA010949, 2005.
Mlynczak, M., Martin-Torres, F. J., Russell, J. M., Beaumont, K., Jacobson, S., Kozyra, J., López-Puertas, M., Funke, B., Mertens, C., Gordley, L., Picard, R., Winick, J. R., Wintersteiner, P., and Paxton, L.: The natural thermostat of nitric oxide emission at $5.3 \mathrm{~mm}$ in the thermosphere observed during the solar storms of April 2002, Geophys. Res. Lett., 30, 21, doi:10.1029/2003GL017693, 2003.

Mlynczak, M. G., Martin-Torres, F. J., Marshall, B. T., Thompson, R. E., Williams, J., Turpin, T., Kratz, D. P., Russell III, J. M., Woods, T., and Gordley, L. L.: Evidence for a solar cycle influence on the infrared energy budget and radiative cooling of the thermosphere, J. Geophys. Res., 112, A12302, doi:10.1029/2006JA012194, 2007.

Mlynczak, M. G., Martin-Torres, F. J., Mertens, C. J., Marshall, B. T., Thompson, R. E., Kozyra, J. U., Remsberg, E. E., Gordley, L. L., Russell III, J. M., and Woods, T.: Solar-terrestrial coupling evidenced by periodic behavior in geomagnetic indexes and the infrared energy budget of the thermosphere, Geophys. Res. Lett., 35, L05808, doi:10.1029/2007GL032620, 2008.

Mlynczak, M. G., Hunt, L. A., Marshall, B. T., Martin-Torres, F. J., Mertens, C. J., Russell III, J. M., Remsberg, E. E., LópezPuertas, M., Picard, R., Winick, J., Wintersteiner, P., Thompson, R. E., and Gordley, L. L.: Observations of infrared radiative cooling in the thermosphere on daily to multiyear timescales from the TIMED/SABER instrument, J. Geophys. Res., 115, A03309, doi:10.1029/2009JA014713, 2010a.

Mlynczak, M. G., Hunt, L. A., Kozyra, J. U., and Russell III, J. M.: Short-term periodic features observed in the infrared cooling of the thermosphere and in solar and geomagnetic indexes from 2002 to 2009, Proc. R. Soc. A, 466, 3409-3419; doi:10.1098/rspa.2010.0077, 2010b.

Pedatella, N. M. and Forbes, J. M.: Electrodynamic Response of the Ionosphere to High-Speed Solar-Wind Streams, J. Geophys. Res., 116, A12310, doi:10.1029/2011JA017050, 2011.

Pedatella, N. M., Lei, J., Thayer, J. P., and Forbes, J. M.: Ionosphere response to recurrent geomagnetic activity: Local time dependency, J. Geophys. Res., 115, A02301, doi:10.1029/2009JA014712, 2010.

Qian, L., Solomon, S. C., and Mlynczak, M. G.: Model simulation of thermospheric response to recurrent geomagnetic forcing, J. Geophys. Res., 115, A10301, doi:10.1029/2010JA015309, 2010.

Ram, T. S., Lei, J., Su, S.-Y., Liu, C. H., Lin, C. H., and Chen, W. S.: Dayside ionospheric response to recurrent geomagnetic activity during the extreme solar minimum of 2008, Geophys. Res. Lett., 37, L02101, doi:10.1029/2009GL041038, 2010.

Sheeley Jr., N. R., Harvey, J. W., and Feldman, W. C.: Coronal holes, solar wind streams, and recurrent geomagnetic disturbances - 1973-1976, Solar Phys., 49, 271-278, 1976.

Sheeley Jr., N. R., Asbridge, J. R., Bame, S. J., and Harvey, J. W.: A pictorial comparison of interplanetary magnetic field polarity, solar wind speed, and geomagnetic disturbance index during the sunspot cycle, Solar Phys., 52, 485-495, 1977.

Sobral, J. H. A., Abdu, M. A., Gonzalez, W. D., Gonzalez, A. C., Tsurutani, B. T., da Silva, R. R. L., Barbosa, I. G., Arruda, D. C. S., Denardini, C. M., Zamlutti, C. J., and Guarnieri, F.: Equatorial ionospheric responses to high-intensity long-duration auroral electrojet activity (HILDCAA), J. Geophys. Res., 111, A07S02, doi:10.1029/2005JA011393, 2006. 
Sojka, J. J., McPherron, R. L., van Eyken, A. P., Nicolls, M. J., Heinselman, C. J., and Kelly, J. D.: Observations of ionospheric heating during the passage of solar coronal hole fast streams, Geophys. Res. Lett., 36, L19105, doi:10.1029/2009GL039064, 2009.

Solomon, S. C., Barth, C. A., and Bailey, S. M.: Auroral production of nitric oxide measured by the SNOE satellite, Geophys. Res. Lett., 26, 1259-1262, 1999.

Solomon, S. C., Woods, T. N., Didkovsky, L. V., Emmert, J. T., and Qian, L.: Anomalously low solar extreme ultraviolet irradiance and thermospheric density during solar minimum, Geophys. Res. Lett., 37, L16103, doi:10.1029/2010GL044468, 2010.

Solomon, S. C., Burns, A. G., Emery, B. A., Mlynczak, M. G., Qian, L., Wang, W., Weimer, D. R., and Wiltberger, M.: Modeling studies of the impact of high-speed streams and co-rotating interaction regions on the thermosphere-ionosphere, J. Geophys. Res., 117, A00L11, doi:10.1029/2011JA017417, 2012.

Soraas, F., Aarsnes, K., Oksavik, K., Sandanger, M. I., Evans, D. S., and Greer, M. S.: Evidence for particle injection as the cause of Dst reduction during HILDCAA events, J. Atmos. Solar Terr. Phys., 66, 177, doi:10.1016/j.jastp.2003.05.001, 2004.

Sugiura, M. and Chapman, S.: The average morphology of geomagnetic storms with sudden commencement, Abhandl. Akad. Wiss. Goettingen Math. Physik. K1., 4, 51-53, 1960.

Temmer, M., Vrsnak, B., and Veronig, A. M.: Periodic appearance of coronal holes and the related variation of solar wind parameters, Solar Phys., 241, 371, doi:10.1007/s11207-007-0336-1, 2007.

Thayer, J. P., Lei, J., Forbes, J. M., Sutton, E. K., and Nerem, R. S.: Thermospheric density oscillations due to periodic solar wind high-speed streams, J. Geophys. Res., 113, A06307, doi:10.1029/2008JA013190, 2008.

Tsurutani, B. T. and Gonzalez, W. D.: The cause of high-intensity long-duration continuous AE activity (HILDCAAs): interplanetary Alfvén wave trains, Planet. Space Sci., 35, 405-412, 1987.

Tsurutani, B. T., Gonzalez, W. D., Gonzalez, A. L. C., Tang, F., Arballo, J. K., and Okada, M.: Interplanetary origin of geomagnetic activity in the declining phase of the solar cycle, J. Geophys. Res., 100, 21717-21733, 1995.

Tsurutani, B. T., Gonzalez, W. D., Guarnieri, F., Kamide, Y., Zhou, X., Arballo, J. K.: Are high-intensity long-duration continuous AE activity (HILDCAA) events substorm expansion events?, J. Atmos. Solar Terr.-Phys., 66, 167-176, 2004a.

Tsurutani, B. T., Mannucci, A., Iijima, B., Abdu, M. A., Sobral, J. H. A., Gonzalez, W. D., Guarnieri, F. L., Tsuda, T., Saito, A., Yumoto, K., Fejer, B., Fuller-Rowell, T. J., Kozyra, J., Foster, J. C., Coster, A. J., and Vasyliūnas, V. M.: Global dayside ionospheric uplift and enhancement associated with interplanetary electric fields, J. Geophys. Res., 109, A08302, doi:10.1029/2003JA010342, 2004b.

Tsurutani, B. T., Gonzalez, W. D., Gonzalez, A. L. C., Guarnieri, F. L., Gopalswamy, N., Grande, M., Kamide, Y., Kasahara, Y., Lu, G., McPherron, R., Soraas, F., and Vasyliunas, V.: Corotating solar wind streams and recurrent geomagnetic activity: a review, J. Geophys. Res., 111, A07S01, doi:10.1029/2005JA011273, 2006 .

Tsurutani, B. T., Mannucci, A. J., Iijima, B. A., Komjathy, A., Saito, A., Tsuda, T., Verkhoglyadova, O. P., Gonzalez, W. D., and Guarnieri, F. L.: Dayside ionospheric (GPS) response to corotat- ing solar wind streams, in: Recurrent Magnetic Storms: Corotating Solar Wind Streams, edited by: Tsurutani, B. T., McPherron, R. L., Gonzalez, W. D., Lu, G., Sobral, J. H. A., and Gopalswamy, N., Amer. Geophys. U. Monograph, Wash. D.C., 167, 245-270, 2006b.

Tsurutani, B. T., McPherron, R. L., Gonzalez, W. D., Lu, G., Gopalswamy, N., and Guarnieri, F. L.: Magnetic storms caused by corotating solar wind streams, in: Recurrent Magnetic Storms, Corotating Solar Wind Streams, edited by: Tsurutani, B. T., McPherron, R., Gonzalez, W., Lu, G., Sobral, J. H. A., and Gopalswamy, N., Geophys. Monogr., 167, AGU, Washington, 1$17,2006 \mathrm{c}$.

Tsurutani, B. T., Verkhoglyadova, O. P., Mannucci, A. J., Saito, A., Araki, T., Yumoto, K., Tsuda, T., Abdu, M. A., Sobral, J. H. A., Gonzalez, W. D., McCreadie, H., Lakhina, G. S., and Vasyliūnas, V. M.: Prompt penetration electric fields (PPEFs) and their ionospheric effects during the great magnetic storm of October 30-31, 2003, J. Geophys. Res., 113, A05311, doi:10.1029/2007JA012879, 2008.

Tsurutani, B. T., Echer, E., and Gonzalez, W. D.: The solar and interplanetary causes of the recent minimum in geomagnetic activity (MGA23): a combination of midlatitude small coronal holes, low IMF $B_{Z}$ variances, low solar wind speeds and low solar magnetic fields, Ann. Geophys., 29, 839-849, doi:10.5194/angeo-29839-2011, 2011a.

Tsurutani, B. T., Echer, E., Guarnieri, F. L., and Gonzalez, W. D.:, The properties of two solar wind high speed streams and related geomagnetic activity during the declining phase of solar cycle 23, J. Atmos. Solar-Terr. Phys., 73, 164-177, 2011 b.

Turner, N. E., Mitchell, E. J., Knipp, D. J., and Emery, B. A.: Energetics of magnetic storms driven by corotating interaction regions: a study of geoeffectiveness, in: Recurrent Magnetic Storms, Corotating Solar Wind Streams, edited by: Tsurutani, B. T., McPherron, R., Gonzalez, W., Lu, G., Sobral, J. H. A., and Gopalswamy, N., Geophys. Monogr., 167, AGU, Washington, 113-124, 2006.

Turner, N. E., Cramer, W. D., Earles, S. K., and Emery, B. A.: Geoefficiency and energy partitioning in CIR-driven and CMEdriven storms, J. Atmos. Solar-Terr. Phys., 71, 1023-1031, 2009.

Vasyliūnas, V. M.: Electric field and plasma flow: What drives what?, Geophys. Res. Lett., 28, 2177-2180, 2001.

Vasyliūnas, V. M.: Physics of magnetospheric variability, Space Sci. Rev., 158, 91-118, doi:10.1007/s11214-010-9696-1, 2011.

Verkhoglyadova, O. P., Tsurutani, B. T., and Mannucci, A. J.: Temporal development of dayside TEC variations during the October 30, 2003 superstorm, Adv. Geosci., edited by: Duldig, M., World Scientific Co., Pte. Ltd., Singapore, 8, 69-77, 2006.

Verkhoglyadova, O. P., Tsurutani, B. T., Mannucci, A. J., Saito, A., Araki, T., Anderson, D., Abdu, M., and Sobral, J. H. A.: Simulation of PPEF Effects in Dayside Low-Latitude Ionosphere for the October 30, 2003 Superstorm, in: Midlatitude Ionospheric Dynamics and Disturbances, edited by: Kintner, P., Coster, A., Fuller-Rowell, T., Mannucci, A., Mendillo, M., and Heelis, R., Geophysical Monograph, 181, 169-177, 2008.

Verkhoglyadova, O. P., Tsurutani, B. T., Mannucci, A. J., Mlynczak, M. G., Hunt, L. A., Komjathy, A., and Runge, T.: Ionospheric VTEC and thermospheric infrared emission dynamics during corotating interaction region and high-speed stream intervals at solar minimum: 25 March to 26 April 2008, J. Geophys. Res., 
116, A09325, doi:10.1029/2011JA016604, 2011.

Wang, W., Lei, J., Burns, A. G., Qian, L., Solomon, S. C., Wiltberger, M., and Xu, J.: Ionospheric Day-to-day Variability around the Whole Heliosphere Interval in 2008, Solar. Phys., 274, 457-472, doi:10.1007/s11207-011-9747-0, 2011.

Wanliss, J. A. and Showalter, K. M.: High-resolution global storm index: Dst versus SYM-H, J. Geophys. Res., 111, A02202, doi:10.1029/2005JA011034, 2006.

Wei, Y., Hong, M., Wan, W., Du, A., Lei, J., Zhao, B., Wang, W., Ren, Z., and Yue, X.: Unusually long lasting multiple penetration of interplanetary electric field to equatorial ionosphere under oscillating IMF $B_{\mathrm{Z}}$, Geophys. Res. Lett., 35, L02102, doi:10.1029/2007GL032305, 2008.
Zhao, B., Wan, W., Liu, L., Mao, T., Ren, Z., Wang, M., and Christensen, A. B.: Features of annual and semiannual variations derived from the global ionospheric maps of total electron content, Ann. Geophys., 25, 2513-2527, doi:10.5194/angeo-252513-2007, 2007. 